\title{
A Large-Conductance Calcium-Selective Mechanotransducer Channel in Mammalian Cochlear Hair Cells
}

\author{
Maryline Beurg, ${ }^{1}$ Michael G. Evans, ${ }^{2}$ Carole M. Hackney, ${ }^{2}$ and Robert Fettiplace ${ }^{3}$ \\ ${ }^{1}$ Equipe Associée 3665 Université Victor Segalen Bordeaux 2, Institut National de la Santé et de la Recherche Médicale, Unité 587, Hôpital Pellegrin, 33076 \\ Bordeaux, France, ${ }^{2}$ Institute of Science and Technology in Medicine, School of Life Sciences, Keele University, Staffordshire ST5 5BG, United Kingdom, and \\ ${ }^{3}$ Department of Physiology, University of Wisconsin Medical School, Madison, Wisconsin 53706
}

\begin{abstract}
Sound stimuli are detected in the cochlea by opening of hair cell mechanotransducer (MT) channels, one of the few ion channels not yet conclusively identified at a molecular level. To define their performance in situ, we measured MT channel properties in inner hair cells (IHCs) and outer hair cells ( $\mathrm{OHCs}$ ) at two locations in the rat cochlea tuned to different characteristic frequencies (CFs). The conductance (in $0.02 \mathrm{~mm}$ calcium) of MT channels from IHCs was estimated as $260 \mathrm{pS}$ at both low-frequency and mid-frequency positions, whereas that from OHCs increased with CFs from 145 to $210 \mathrm{pS}$. The combination of MT channel conductance and tip link number, assayed from scanning electron micrographs, accounts for variation in whole-cell current amplitude for OHCs and its invariance for IHCs. Channels from apical IHCs and OHCs having a twofold difference in unitary conductance were both highly calcium selective but were distinguishable by a small but significant difference in calcium permeability and in their response to lowering ionic strength. The results imply that the MT channel has properties possessed by few known candidates, and its diversity suggests expression of multiple isoforms.
\end{abstract}

Key words: auditory; calcium [Ca]; channel; cochlea; hair cell; mechanosensory; transduction

\section{Introduction}

The mammalian cochlea contains two types of sensory hair cell: inner hair cells (IHCs) that transmit auditory information to the brain via synapses onto the auditory nerve afferents and outer hair cells (OHCs) with a supplementary motor capacity thought to amplify the vibrations of the basilar membrane (Dallos, 1992; Fettiplace and Hackney, 2006). This dichotomy belies a common sensory mechanism whereby deflection of the stereociliary (hair) bundle of each cell activates mechanotransducer (MT) channels by tensioning the tip links connecting stereocilia in adjacent ranks (Hudspeth, 1989). The MT channel has not yet been identified at a molecular level despite a proposal (Corey et al., 2004) that it is a member of the transient receptor potential (TRP) superfamily, ankyrin-repeat TRP (TRPA1). This claim was recently challenged by the lack of auditory phenotype in TRPA1 knockouts (Bautista et al., 2006; Kwan et al., 2006). It is therefore essential to characterize the channel in situ, an aim of the present work, for comparison with alternative molecular candidates. Features for differentiating between the $\sim 30$ members of the TRP channel superfamily, several of which display mechanosensitive properties (Sukharev and Corey, 2004), include single-channel conductance, ionic selectivity, modula-

Received May 23, 2006; revised Sept. 10, 2006; accepted Sept. 11, 2006.

This work was supported by National Institute on Deafness and Other Communication Disorders Grant R01 DC 01362 (R.F.). C.M.H. and M.G.E. were supported by a grant from Deafness Research (United Kingdom). We thank Dr. David Furness (Keele University) for help with the scanning electron microscopy.

Correspondence should be addressed to Robert Fettiplace, 185, Medical Sciences Building, 1300 University Avenue, Madison, WI 53706. E-mail: fettiplace@physiology.wisc.edu.

DOI:10.1523/JNEUROSCI.2188-06.2006

Copyright $\odot 2006$ Society for Neuroscience ～0270-6474/06/2610992-09\$15.00/0 tion by calcium, and specific blocking agents (Clapham et al., 2005; Owsianik et al., 2006). These characteristics also set the TRP channel superfamily apart from other candidates, such as the epithelial $\mathrm{Na}^{+}$channel or the cyclic nucleotide-gated channel that mediates transduction in vision and olfaction (Fettiplace and Ricci, 2006). Most of the relevant properties have been measured in nonmammalian hair cells (Corey and Hudspeth, 1979; Ohmori, 1985; Crawford et al., 1991; Ricci et al., 2003; Farris et al., 2004), but there is sparse information for mammalian cochlear hair cells. The one measurement in OHCs indicates an MT single-channel conductance of $>100$ pS (Géléoc et al., 1997). For IHCs, there is an extensive body of work documenting the receptor potentials in vivo (Russell and Sellick, 1978; Dallos, 1986; Russell et al., 1986) but only isolated reports of MT currents elicited by direct manipulation of the hair bundle (Kros et al., 1992, 2002). For example, it is not known whether MT currents of IHCs display fast adaptation like OHCs (Kros et al., 1992; Kennedy et al., 2003) or whether the size and kinetics vary with cochlear location as do those of OHCs (He et al., 2004; Ricci et al., 2005). A number of morphological and functional features of the organ of Corti change along the longitudinal axis of the cochlea, which is known as the tonotopic axis because it reflects spatial separation of the different frequency components in a sound stimulus. The purpose of the present work was to compare both macroscopic and single-channel MT currents in IHCs and $\mathrm{OHCs}$ at cochlear locations encoding different frequencies. We show that the MT currents in the two hair cell types can be primarily understood in terms of differences in single-channel properties and hair-bundle morphology derived from scanning electron micrographs. 


\section{Materials and Methods}

Experiments were performed on inner and outer hair cells from isolated coils of the organ of Corti of Sprague Dawley rats between postnatal day 6 (P6) and P11 with techniques reported previously (Kennedy et al., 2003; Ricci et al., 2005). Animals were anesthetized with halothane and killed by decapitation using methods approved by the Institutional Animal Care and Use Committee of the University of Wisconsin. Cochlear coils were isolated by removing the bone from the apical and middle turns, unpeeling the stria vascularis and, after a 5-10 min incubation in saline containing $30 \mu \mathrm{g} / \mathrm{ml}$ bacterial subtilisin protease (type XXIV; Sigma, St. Louis, MO), lifting off the tectorial membrane. Excised apical or middle turns were fixed in the experimental chamber with strands of dental floss and viewed through a $40 \times$ long working distance waterimmersion objective (numerical aperture 0.8 ) on a Zeiss (Oberkochen, Germany) Axioskop FS microscope. The chamber was perfused with artificial perilymph of the following composition (in $\mathrm{mm}$ ): $154 \mathrm{NaCl}, 6$ $\mathrm{KCl}, 1.5 \mathrm{CaCl}_{2}, 2 \mathrm{Na}$-pyruvate, 8 glucose, and $10 \mathrm{Na}-\mathrm{HEPES}, \mathrm{pH}$ 7.4. The apical surface of the organ of Corti was separately superfused through a $100 \mu \mathrm{m}$ pipette with one of several solutions: (1) a normal solution identical to the artificial perilymph containing $1.5 \mathrm{mM} \mathrm{Ca}^{2+}$; (2) a reduced calcium solution [in mm: $150 \mathrm{NaCl}, 6 \mathrm{KCl}, 3.3 \mathrm{CaCl}_{2}, 4 \mathrm{Na}-\mathrm{N}$ hydroxyethylethylenediaminetriacetic acid (HEDTA), $2 \mathrm{Na}$-pyruvate, 8 glucose, and $10 \mathrm{Na}$-HEPES, pH 7.4] that had an estimated free $\mathrm{Ca}^{2+}$ of $20 \mu \mathrm{M}$ (buffered with HEDTA) similar to that in rat endolymph (Bosher and Warren, 1978); (3) a high calcium solution [in mM: $100 \mathrm{CaCl}_{2}, 15$ Tris-Cl or $\mathrm{N}$-methyl glucamine (NMG), and 20 glucose, $\mathrm{pH} 7.4]$; (4) a modified monovalent solution (in mM: $1.5 \mathrm{CaCl}_{2}, 160 \mathrm{NMG}$, and 8 glucose, $\mathrm{pH} 7.4$ ); or (5) a solution of reduced ionic strength (in mM: $45 \mathrm{NaCl}$, $6 \mathrm{KCl}, 1.5 \mathrm{CaCl}_{2}, 8$ glucose, 200 sucrose, and $10 \mathrm{Na}$-HEPES, pH 7.4).

To isolate single mechanotransducer channels in a whole-cell recording, saline with submicromolar free $\mathrm{Ca}^{2+}$ (containing $140 \mathrm{~mm} \mathrm{NaCl}, 6$ mм KCl, $1.8 \mathrm{~mm} \mathrm{CaCl}_{2}$, $5 \mathrm{~mm} \mathrm{Cs}_{4}$ BAPTA, $8 \mathrm{~mm}$ glucose, $10 \mathrm{~mm} \mathrm{Na-}$ HEPES, $\mathrm{pH} 7.4$, and $0.1 \mu \mathrm{M}$ free $\mathrm{Ca}^{2+}$ ) was pressure ejected onto the hair bundles for 1-2 s to sever most of the tip links (Ricci et al., 2003). After this manipulation, in the best cases, a single-channel level was discernable, but in some recordings, multiple (two, three, or four) channel levels were evident. To obtain an accurate estimate of the single-channel amplitude, most measurements were made on individual traces, selecting longer-duration events that appeared to reach their full amplitude. The ability to discriminate unitary events depended critically on the current noise in the whole-cell recording, which in practice was dominated by the current noise in the leak conductance (rather than the theoretical limit set by the series resistance and cell capacitance). Because of an increase in current noise in $0.02 \mathrm{~mm}$ calcium, probably attributable to an effect on the seal resistance, it was not possible to obtain an accurate estimate of single-channel conductance in endolymphatic calcium.

Borosilicate patch electrodes connected to an Axopatch 200A amplifier (Molecular Devices, Palo Alto, CA) were introduced through a small hole in the reticular lamina. Most recordings were made from IHCs or first-row OHCs either at the beginning of the apical turn, $\sim 0.8$ of the distance along the basilar membrane from the base, or in the middle turn, 0.5 of the distance from the base. From the place-frequency map in adult rats, the recording sites correspond to characteristic frequencies of $\sim 4$ and $14 \mathrm{kHz}$, respectively (Müller, 1991). Measurements were also attempted in the basal turn, but the cells deteriorated rapidly, and, for this reason, we felt the results were not reliable and have not included them. Patch pipettes were filled with an intracellular solution of the following composition (in mM): $142 \mathrm{CsCl}, 2 \mathrm{MgCl}_{2}, 1$ EGTA, $3 \mathrm{Na}_{2} \mathrm{ATP}, 0.5$ $\mathrm{Na}_{2} \mathrm{GTP}$, and 10 Cs-HEPES, pH 7.2. Patch pipettes had starting resistances of 3-6 $\mathrm{M} \Omega$, and up to $70 \%$ series-resistance compensation was applied. Macroscopic MT currents were low-pass filtered at the output of the Axopatch 200A amplifier at $10 \mathrm{kHz}$. Single-channel currents were filtered at $5 \mathrm{kHz}$, and no series resistance compensation was applied. All membrane potentials were corrected off-line for the uncompensated series resistance and for the junction potential with respect to the $\mathrm{CsCl}$ intracellular of the apical perfusate: (1) normal perilymph, $-4 \mathrm{mV}$; (2) low $(0.02 \mathrm{~mm})$ calcium perilymph, $-4 \mathrm{mV}$; (3) high ( $100 \mathrm{~mm})$ calcium, $-9 \mathrm{mV}$; and (4) modified monovalent, $\mathrm{NMG},-12 \mathrm{mV}$. Hair cells were

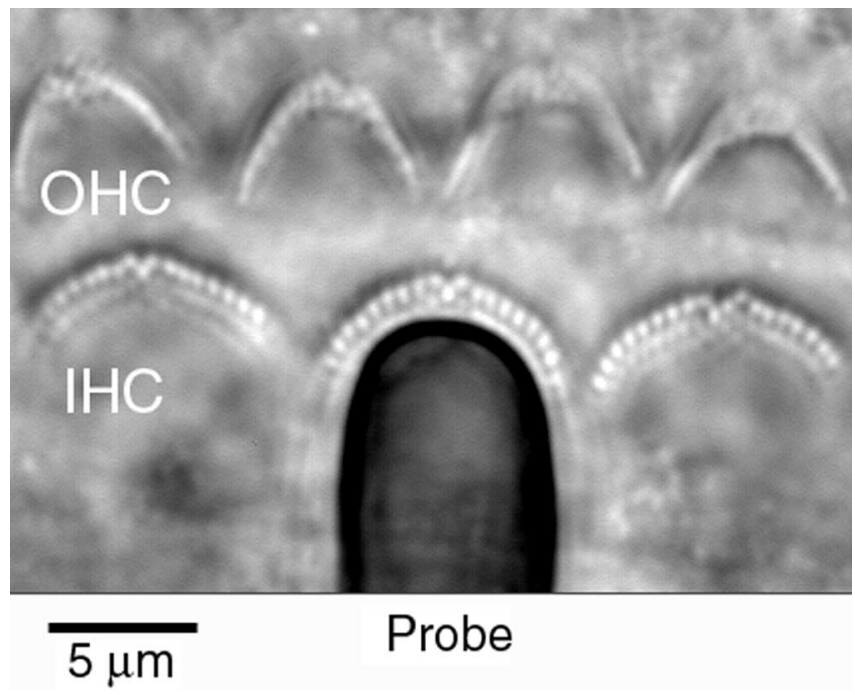

Figure 1. Method for mechanically stimulating inner hair cell bundles. A view of the rat organ of Corti from the apical region showing hair bundles of three IHCs and four row-One $\mathrm{OHCs}$ is shown. The IHC can be deflected with a fire-polished glass probe $\sim 6 \mu$ m in diameter that fits into the broad U-shaped hair bundle. The other end of the probe is attached to a piezoelectric stack actuator. For the outer hair cells, a smaller probe, $\sim 3 \mu \mathrm{m}$ diameter, is adequate. Note that at least three rows of stereocilia can be seen on the IHC bundles. The postnatal age of the rat was $\mathrm{P} 8$.

whole-cell voltage clamped at holding potentials between -80 and -120 $\mathrm{mV}$ at room temperature $\left(19-22^{\circ} \mathrm{C}\right)$. Current-voltage relationships for the MT channel were derived by delivering saturating negative and positive hair bundle displacement steps, $3 \mathrm{~ms}$ in duration, during a $200 \mathrm{mV}$ voltage ramp. Plots of current-voltage relationships were fit with a thirdorder polynomial to estimate the reversal potential $\left(V_{\text {rev }}\right)$. Relative permeabilities were calculated using the Goldman-Hodgkin-Katz (GHK) equation in which the currents carried by different ions sum to 0 at the reversal potential (Jackson, 2006). The permeability of the channel for $\mathrm{Ca}^{2+}\left(P_{\mathrm{Ca}}\right)$ relative to $\mathrm{Cs}^{+}\left(P_{\mathrm{Cs}}\right)$ was calculated from the reversal potential in $100 \mathrm{~mm}$ extracellular calcium using the GHK equation in the following form (Owsianik et al., 2006): $P_{\mathrm{Ca}} / P_{\mathrm{Cs}}=\left\{\left[\mathrm{Cs}^{+}\right]_{\mathrm{i}} / 4\left[\mathrm{Ca}^{2+}\right]_{\mathrm{o}}\right\}$ $\left\{\exp \left(V_{\text {rev }} F / R T\right)\right\}\left\{\exp \left(V_{\text {rev }} F / R T\right)+1\right\}$, where $R, T$, and $F$ have their usual thermodynamic meanings. This analysis assumes that $\mathrm{Ca}^{2+}$ is the only extracellular permeant ion and $\mathrm{Cs}^{+}$is the only intracellular permeant. The small amount of intracellular $\mathrm{Na}^{+}$derived from ATP and GTP was assumed to have approximately the same permeability as $\mathrm{Cs}^{+}$(Ohmori, 1985), and its concentration was included in the total intracellular concentration of $\mathrm{Cs}^{+}$. The ion concentrations in the above equation should strictly be activities; these were determined using activity coefficients for $0.1 \mathrm{M} \mathrm{CaCl}_{2}$ (0.518) and $0.16 \mathrm{M} \mathrm{CsCl}(0.725)$ obtained from standard tables (Robinson and Stokes, 1965). Mechanotransducer currents were digitized with a Power1401 at $150 \mathrm{kHz}$ (Cambridge Electronics Design, Cambridge, UK) and analyzed with IgorPro version 4.00 (WaveMetrics, Lake Oswego, OR). All records are averages of 10 stimulus presentations, and, unless otherwise indicated, results are expressed as mean $\pm 1 \mathrm{SD}$. Statistical significance was assessed by a two-tailed $t$ test with $p<0.05$.

Hair bundles were deflected by the axial motion of a glass pipette waxed to and driven by a piezoelectric stack actuator (model P-802; Physik Instrumente, Karlsruhe, Germany). For measurements on OHCs, the tip of the pipette was fire polished to $\sim 3 \mu \mathrm{m}$ in diameter so as to fit into the V-shaped stereociliary bundle, whereas for IHCs, a larger pipette, $\sim 6 \mu \mathrm{m}$ in diameter, was used to better stimulate the wider hair bundle. There was some variation depending on the preparation and postnatal age in the shape of the IHC bundle, ranging from a U-shaped one like the OHC (Fig. 1) to a straight one seen in IHCs of older animals. To optimally stimulate the bundle and contact all the stereocilia, most of the measurements of macroscopic IHC currents were performed on $\mathrm{U}$-shaped bundles (P9 or younger) for which the $6 \mu \mathrm{m}$ probe fitted well the shape of the bundle (Fig. 1). Nevertheless, there was no large difference between the mean currents with age (e.g., $0.0 .99 \pm 0.2$ for three P6 
A outer hair cell (apex)
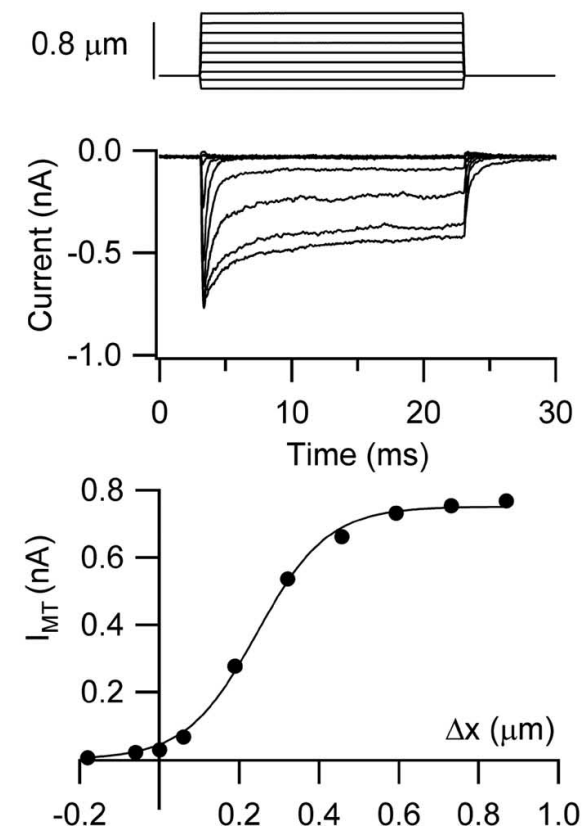

B inner hair cell (apex)
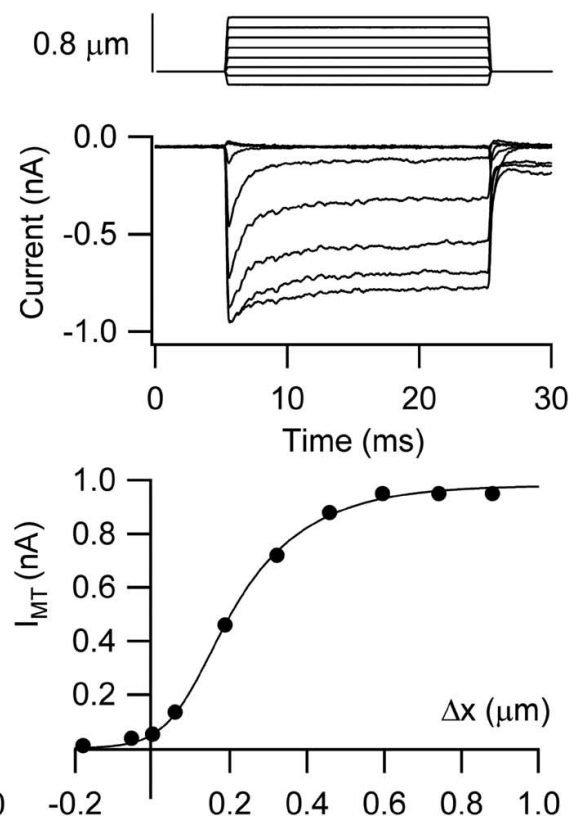

C inner hair cell (middle)

Figure 2. Comparison of MT currents from inner and outer hair cells. $A$, Responses of an $\mathrm{OHC}$ in the apical turn tuned to $\sim 4 \mathrm{kHz}$. $\boldsymbol{B}$, Responses of an IHC, also from the apical turn. $\boldsymbol{C}$, Responses of an IHC in the middle turn tuned to $\sim 14 \mathrm{kHz}$. Each panel shows average currents in response to hair bundle deflections, positive steps for motion away from the modiolus. Note that adaptation is faster in the apical $\mathrm{OHC}$ than in the apical IHC. The relationship between peak MT current, $I$, and bundle displacement, $X$, is shown at the bottom. Smooth curves are as follows. $A, I=I_{\text {max }} /[1+$ $\exp \left(z_{0} \times\left(X_{0}-X\right)\right]$, where $I_{\max }=0.75 \mathrm{nA}, z_{0}=11.3 \mu \mathrm{m}^{-1}$, and $X_{0}=0.24 \mu \mathrm{m} . B, C, I=I_{\max } /\left[1+\left\{\exp \left(z_{0} \times\left(X_{0}-X\right)\right)\right\}\left\{1+\exp \left(z_{1} \times\left(X_{1}-X\right)\right)\right\}\right]$, where $(B) I_{\max }=0.98 \mathrm{nA}, z_{0}=6.5$ $\mu \mathrm{m}^{-1}, z_{1}=13 \mu \mathrm{m}^{-1}$, and $X_{0}=X_{1}=0.14 \mu \mathrm{m}$, and $(\boldsymbol{C}) I_{\max }=0.76 \mathrm{nA}, z_{0}=5 \mu \mathrm{m}^{-1}, z_{1}=20 \mu \mathrm{m}^{-1}$, and $X_{0}=X_{1}=0.13 \mu \mathrm{m}$. Postnatal ages were P7 (A), P8 (B), and P8 (C).

cells compared with $0.81 \pm 0.03$ for three P10 cells). The piezoelectric actuator was driven with voltage steps that were filtered with an eightpole Bessel filter set at a frequency, $F_{\mathrm{B}}$, of $2-5 \mathrm{kHz}$ to remove oscillations attributable to lateral resonances of the glass pipette. The time course of motion of each glass probe was calibrated by projecting its image onto a pair of photodiodes as described previously (Crawford and Fettiplace, 1985). In response to a voltage step filtered at $F_{\mathrm{B}}$, the mechanical displacement had a $10-90 \%$ rise time of $0.08-0.2 \mathrm{~ms}$.

Scanning electron micrographs of IHC and OHC hair bundles from $\mathrm{P} 10$ and P15 rats were prepared and examined using techniques modified from Furness and Hackney (1986) in accordance with the United Kingdom Animals (Scientific Procedures) Act of 1986. Rats were killed with an intraperitoneal injection of sodium pentobarbitone (Pentoject; 100 $\mathrm{mg} / \mathrm{kg}$ ) and decapitated. The auditory bullae were exposed, a small hole was made in the apex of each cochlea, and the round and oval windows were opened with a fine needle. The cochlea was fixed by perfusion through the apical hole with $2.5 \%$ electron-microscopic-grade glutaraldehyde in $0.1 \mathrm{M}$ sodium cacodylate buffer, $\mathrm{pH} 7.4$, plus $2 \mathrm{mM} \mathrm{CaCl}_{2}$ and subsequently stored at $4^{\circ} \mathrm{C}$ in a $10 \%$ dilution of the original fixative. The cochlea was later dissected by removing the bony shell, postfixed for $2 \mathrm{~h}$ at room temperature in $1 \%$ osmium tetroxide in cacodylate buffer, washed six times in distilled water, and placed in a saturated filtered solution of thiocarbohydrazide for $20 \mathrm{~min}$. This procedure was repeated followed by a final set of washes, $2 \mathrm{~h}$ in $\mathrm{OsO}_{4}$, and transferred to $70 \%$ ethanol. It was then dehydrated through an ethanolic series, critical point dried from liquid $\mathrm{CO}_{2}$, and mounted on scanning electron microscope stubs using silver DAG electroconductive paint. The specimen was examined in a Hitachi (Tokyo, Japan) S-4500 field emission scanning electron microscope operated at an accelerating voltage of $5 \mathrm{kV}$. Stereociliary counts were made on hair bundles from IHCs and OHCs at each of the cochlear locations studied electrophysiologically.

\section{Results}

Comparison MT currents of inner and outer hair cells

Step deflections of the hair bundle of IHCs elicited rapidly developing MT currents that displayed fast adaptation resembling that of OHCs (Fig. 2) (Kennedy et al., 2003). MT currents were graded with bundle displacement up to $\sim 500 \mathrm{~nm}$, with peak amplitudes similar in cells from apical and middle turn locations tuned to CFs of 4 and $14 \mathrm{kHz}$, respectively. Current-displacement relationships were fitted with three-state Boltzmann functions (Fig. 2) with fitting parameters similar to those used for turtle hair cells when also stimulated with a stiff glass probe (Ricci and Fettiplace, 1997). A several-fold narrower activation curve has been described for both turtle (Ricci et al., 2002) and mammalian (Russell et al., 1992; Géléoc et al., 1997) cochlear hair cells when using force stimuli administered with a flexible fiber or water jet, but the reason for this difference compared with the stiff stimulating probe is not known. A feature of the IHC responses is that they often displayed a slow offset component for the largest displacements (see Figs. $4 B, 9 B$ ), a property also displayed by turtle hair cells (Crawford et al., 1989). The mean IHC current, measured at a holding potential of $-84 \mathrm{mV}$, was $0.95 \pm 0.17 \mathrm{nA}(n=17)$ at the low-frequency position and $0.83 \pm 0.12 \mathrm{nA}(n=7)$ at the mid-frequency position. The largest current measured at each of the locations was 1.24 and $1.02 \mathrm{nA}$. There was no difference in the fast adaptation time constants, with mean values of $0.41 \pm 0.11$ $\mathrm{ms}$ at the low-frequency position and $0.45 \pm 0.20 \mathrm{~ms}$ at the midfrequency position. The findings on the IHCs contrast with those in the OHCs in which the MT current at the high-frequency location was twice as large and the adaptation rate twice as fast as at the low-frequency location (Ricci et al., 2005). This difference in the OHC MT current size was confirmed here, with mean values of $0.78 \pm 0.13 \mathrm{nA}(n=16)$ at the low-frequency position and $1.2 \pm 0.2 \mathrm{nA}(n=8)$ at the mid-frequency position, both at $-84 \mathrm{mV}$ holding potential. The largest $\mathrm{OHC}$ current recorded at the two locations was 0.90 and $1.47 \mathrm{nA}$, respectively. The fast adaptation time constant for OHCs from all positions was faster 


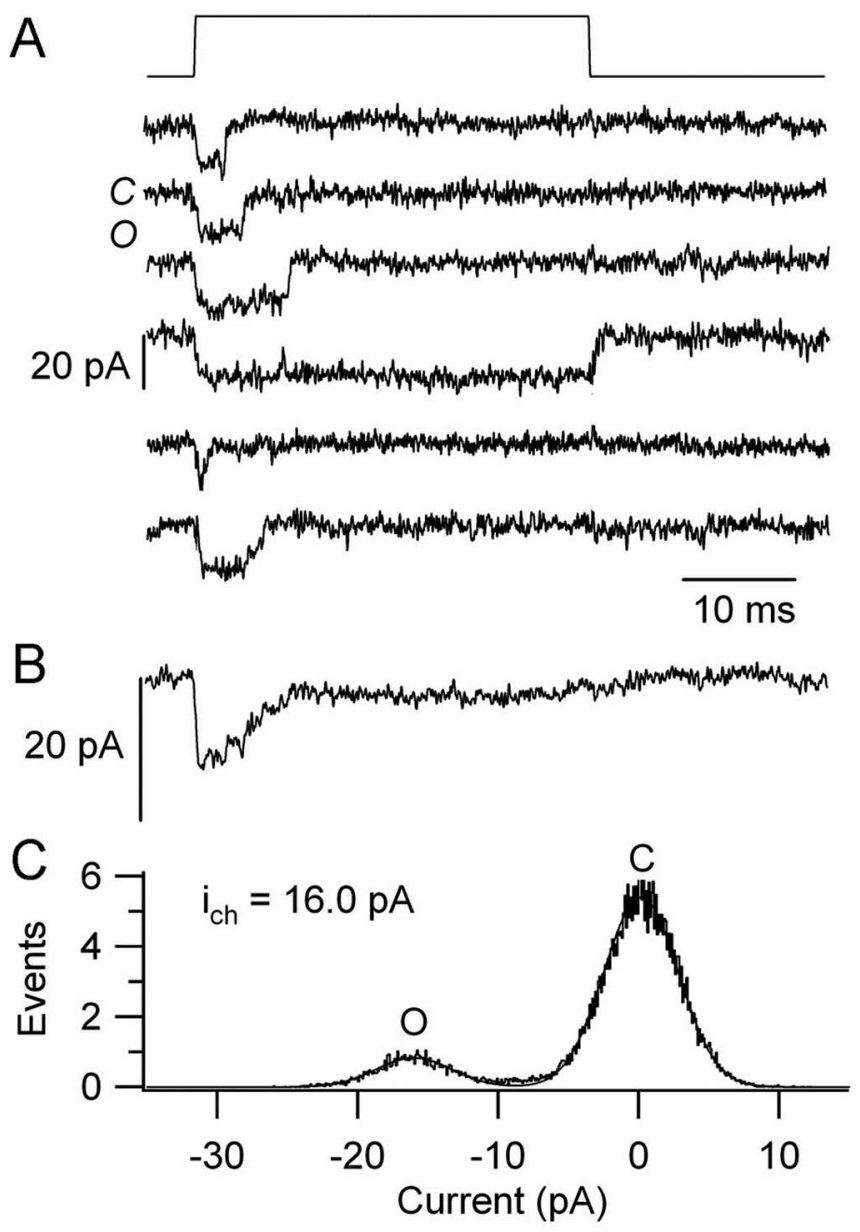

Figure 3. Single MT channels in an apical-turn inner hair cell. $\boldsymbol{A}$, Examples of unitary responses to a hair bundle displacement showing closed $(C)$ and open $(0)$ states of the channel. The time course of the $0.6 \mu \mathrm{m}$ displacement step is shown at the top. Examples were chosen to illustrate full openings. $\boldsymbol{B}$, Average response to 10 stimuli. Peak current was 12 pA. C, Amplitude histogram of responses fitted with a pair of Gaussians indicates a single-channel current of 16 $\mathrm{pA}$, with a holding potential of $-84 \mathrm{mV}$. The postnatal age of the rat was P10.

than for IHCs. For example, even under the same stimulus filtering conditions, the adaptation time constant for apical OHCs using small mechanical steps was $0.17 \pm 0.04 \mathrm{~ms}$, faster than IHCs from either cochlear location (Fig. 2). The results suggest a difference in the tonotopic organization of IHCs and OHCs.

\section{Single mechanotransducer channels}

Possible differences in MT channel properties that might contribute to the tonotopic variation in macroscopic currents were explored by measuring single channels. Channels were recorded in whole-cell mode after destruction of most of the tip links and side links by brief exposure to submicromolar calcium (Assad et al., 1991; Crawford et al., 1991; Ricci et al., 2003). In a proportion of attempts, it was possible to isolate single channels, the open probability of which could be modulated by deflections of the hair bundle (Figs. 3, 4). For IHCs, large single-channel events up to $16 \mathrm{pA}$ in size were obtained in normal $(1.5 \mathrm{~mm})$ calcium external solution. The open probability increased for hair bundle displacements over a range similar to the whole-cell current (Fig. $4 C)$, and the ensemble averages usually displayed fast adaptation (Fig. $4 B$ ) with a time constant in the range of those observed for macroscopic currents. For example, the ensemble averages in Figure $4 B$ had adaptation time constants for the two smallest stimuli of 0.49 and $0.66 \mathrm{~ms}$ compared with $0.45 \mathrm{~ms}$ for the macroscopic current. In addition, channel activity was abolished by perfusion with $0.2 \mathrm{~mm}$ dihydrostreptomycin (data not shown), an established known blocker of the MT channel in mammalian auditory hair cells (Kros et al., 1992). The only other channel type with a conductance as large as that observed is the $\mathrm{Ca}^{2+}$-activated $\mathrm{K}^{+}(\mathrm{BK})$ channel, which is present in adult IHCs. However, the $\mathrm{BK}$ channel would not be activated at $-84 \mathrm{mV}$, would have a much smaller conductance for inward $\mathrm{Na}^{+}$, and would be blocked by $\mathrm{Cs}^{+}$in the intracellular solution (Skinner et al., 2003; Marcotti et al., 2004; Pyott et al., 2004). These various observations argue that the unitary events do indeed reflect opening of single MT channels. Comparison of channels measured in IHCs from the apical turn (CF of $4 \mathrm{kHz}$ ) and from the middle turn (CF of $14 \mathrm{kHz}$ ) indicated no significant difference in their channel amplitudes. Mean single-channel currents at $-84 \mathrm{mV}$ were $15.0 \pm 1.6 \mathrm{pA}(n=7$; range, $12.0-16.8 \mathrm{pA})$ at the low-frequency position and $14.7 \pm 1.6$ $\mathrm{pA}(n=5$; range, $12.4-16.3 \mathrm{pA})$ at the mid-frequency position. Assuming a linear current-voltage relationship and a reversal potential of $+3 \mathrm{mV}$ in normal perilymph (see below), the unitary conductance of the IHC MT channel is $\sim 170 \mathrm{pS}$.

Single MT channels were also recorded from OHCs, but, in contrast to IHCs, their amplitude varied with cochlear location and was larger at the location having a higher CF (Fig. 5). Mean single-channel currents at $-84 \mathrm{mV}$ were $8.3 \pm 0.5 \mathrm{pA}(n=3$; range, $7.8-8.8 \mathrm{pA}$ ) at the low-frequency position and $12.1 \pm 1.0$ $\mathrm{pA}(n=3$; range, $11.0-13.0 \mathrm{pA})$ at the mid-frequency position. It might be argued that, as a consequence of rapid channel flickering, the single-channel currents were underestimated because of filtering by the recording system. However, this is unlikely to explain the tonotopic differences in amplitude because the higher CF channels would, if anything, be faster and flicker more and therefore be more filtered. Thus, the higher CF channels would appear smaller than the lower CF rather than larger. The inferred unitary conductances of the OHC MT channels were 95 and 139 pS, values that are within the range of those reported by Géléoc et al. (1997). The differences in both size and tonotopic variation distinguish the MT channels in OHCs from those in IHCs.

\section{Stereocilia and tip links}

MT channels are thought to be activated by an increase in tension in the tip links, extracellular strands that pass from the top of one stereocilium to the adjacent wall of its taller neighbor (Pickles et al., 1984; Hudspeth, 1989). Only a single tip link originates from the top of each stereocilium, although multiple tip links may converge on a taller neighbor (Furness and Hackney, 1985). The number of tip links was estimated by counting all the stereocilia in the bundle and then subtracting from this value the number of stereocilia in the tallest row. Stereocilia in rows other than the tallest were included only if they were in contact with others in the next row (Fig. 6A). Hair bundles of OHCs and IHCs differ in their overall shape and degree of regularity (Fig. 6) (Lim, 1980). Whereas $\mathrm{OHC}$ bundles are composed of three discrete rows of stereocilia with the members of each row having approximately equal diameter, IHC bundles are less organized and the shortest stereocilia are substantially narrower and more numerous than the tallest. A consequence of this difference is that the inferred number of tip links was approximately two-thirds of the number of stereocilia for the OHCs but three-quarters of the number of stereocilia for the IHCs (Table 1).

The number of tip links per bundle was used in conjunction with the macroscopic and single-channel current amplitudes to calculate the number of channels per tip link. For both IHCs and 
OHCs, this number lay between one and two whether the mean or largest value for the macroscopic current was used in the calculation (Table 1). The largest macroscopic currents in each case may represent the best estimate for an undamaged bundle, although the lower number of channels per tip link for IHCs compared with $\mathrm{OHCs}$ from the same region may indicate that the maximum IHC currents are still underestimated. Values of up to two channels per tip link accord with previous results in nonmammalian vertebrates (Howard and Hudspeth, 1988; Denk et al., 1995; Ricci et al., 2003).

\section{Calcium permeability and block}

In view of the variation in single-channels properties, we examined the effects of calcium on macroscopic currents from apical IHCs and OHCs, which show the greatest difference in unitary conductance. Calcium has a dual effect on the MT currents (Eatock et al., 1987; Crawford et al., 1991). Reducing calcium from 1.5 to $0.02 \mathrm{~mm}$, the concentration found in endolymph that bathes the hair bundles in vivo (Bosher and Warren, 1978), both increased the current amplitude and slowed adaptation in IHCs (Fig. 7A). The mean increase in the MT current size was $1.52 \pm 0.12(n=6)$, not statistically different from the increase of $1.58 \pm 0.18$ reported for OHCs (Kennedy et al., 2003). Measurements for both hair cell types are quoted for a holding potential of $-84 \mathrm{mV}$. However, this factor depended on the membrane potential and declined with depolarization, causing the current-voltage relationships in low and high calcium to converge at positive potentials and diverge at more negative membrane potentials (Fig. $7 B$ ). The current-voltage relationship was approximately linear in $1.5 \mathrm{mM} \mathrm{Ca}^{2+}$ but showed inward rectification in $0.02 \mathrm{mM} \mathrm{Ca}^{2+}$.

The calcium-binding site for channel block is probably distinct from that mediating fast adaptation, which is intracellular as indicated by its dependence on membrane potential and intracellular concentration of calcium buffer (Fettiplace and Ricci, 2003). To drive fast adaptation, the MT channels are highly permeable to calcium (Corey and Hudspeth, 1979; Ohmori, 1985; Ricci and Fettiplace, 1998). The calcium selectivity of the mammalian MT channels was assayed in two ways. When $100 \mathrm{~mm}$ calcium was the major permeant ion in the extracellular solution, the reversal potential of the MT current (Fig. 8) for cells in the apical low-frequency region was $27.9 \pm 3.3 \mathrm{mV}(n=5)$ for IHCs and $22.9 \pm 4.6 \mathrm{mV}(n=5)$ in OHCs. The reversal potentials were analyzed in terms of the GHK equation (see Materials and Methods) to yield a permeability ratio for $\mathrm{Ca}^{2+}$ relative to $\mathrm{Cs}^{+}$of 6.9 in
$A$
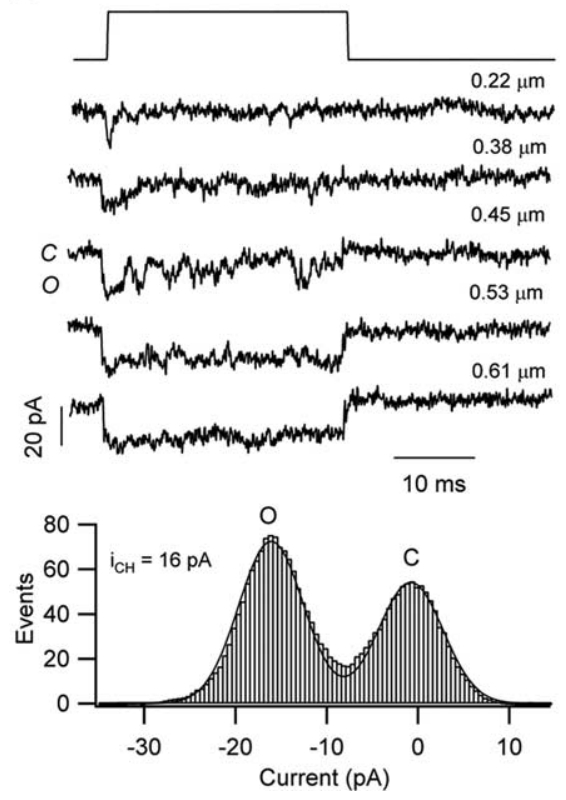

B

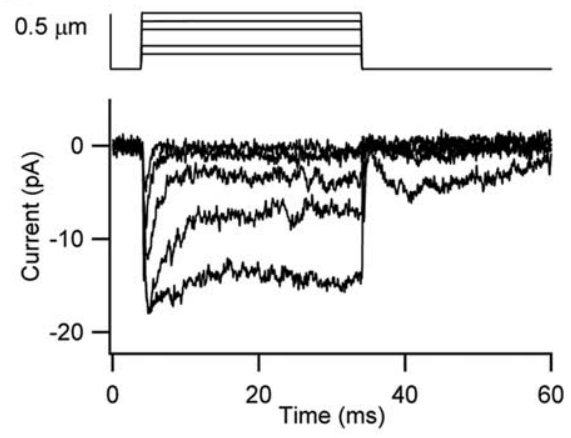

C

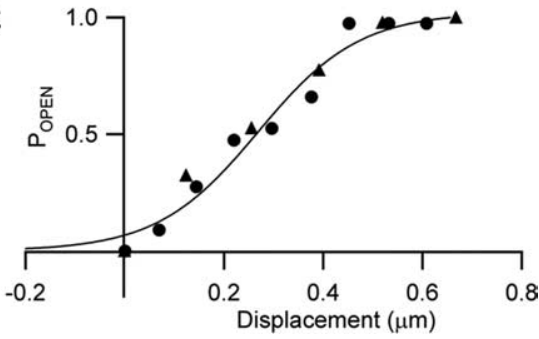

Figure 4. Single MT channels in a middle-turn inner hair cell. $\boldsymbol{A}$, Unitary responses showing closed $(C)$ and open $(0)$ states of the channel for different hair bundle displacements. The amplitude histogram for the two largest stimuli is shown below, indicating a single-channel current of $16 \mathrm{pA}$, with a holding potential of $-84 \mathrm{mV}$. B , Ensemble averages for different hair bundle displacements. Note the fast adaptation in the small responses and the additional activity after the step for the largest. C, Probability of channel opening versus displacement $(X)$ for this channel (circles) and for another channel from an apical inner hair cell (triangles). Smooth curve: $P_{\text {open }}=1 /\left(1+\exp \left(z_{0} \times\left(X_{0}-X\right)\right)\right)$, where $X_{0}=0.27 \mu \mathrm{m}$, and $z_{0}=10 \mu \mathrm{m}^{-1}$. The postnatal age of the rat was $P 10$.
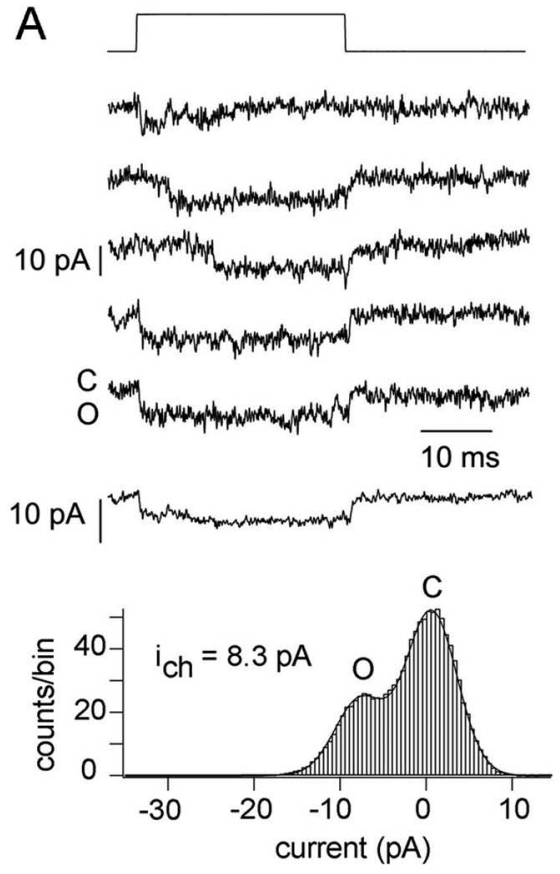

Figure 5. Single MT channels in a two outer hair cells. $\boldsymbol{A}$, Apical turn. $\boldsymbol{B}$, Middle turn. In each case, unitary responses are shown for displacement steps of $0.6 \mu \mathrm{m}$ in $\boldsymbol{A}$ and $0.4 \mu \mathrm{m}$ in $\boldsymbol{B}$. Below the single-channel records are the ensemble average current and the amplitude histogram indicating a single-channel current of $8.3 \mathrm{pA}$ in $\boldsymbol{A}$ and $11.0 \mathrm{pA}$ in $\boldsymbol{B}$. Holding potential of $-84 \mathrm{mV}$. The postnatal ages of the rats were $\mathrm{P} 11(\boldsymbol{A})$ and $\mathrm{P} 8(\boldsymbol{B})$.
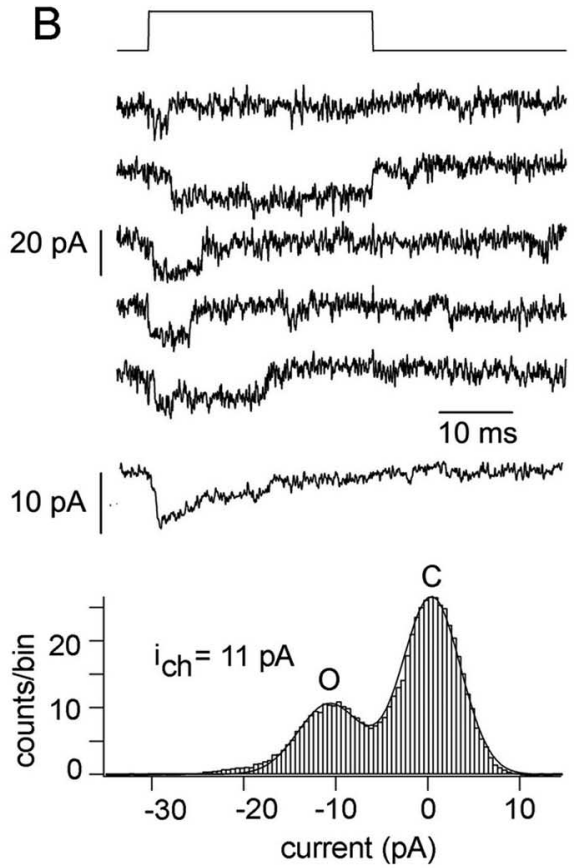

IHCs and 4.9 in OHCs, values similar to that measured in the chick vestibular hair cells (Ohmori, 1985). In normal saline, the MT current reversal potential was $3.1 \pm 2.9 \mathrm{mV}(n=4)$ for IHCs and $2.2 \pm 2.0 \mathrm{mV}(n=7)$ for OHCs.

One additional indication of $\mathrm{Ca}^{2+}$ selectivity was obtained 


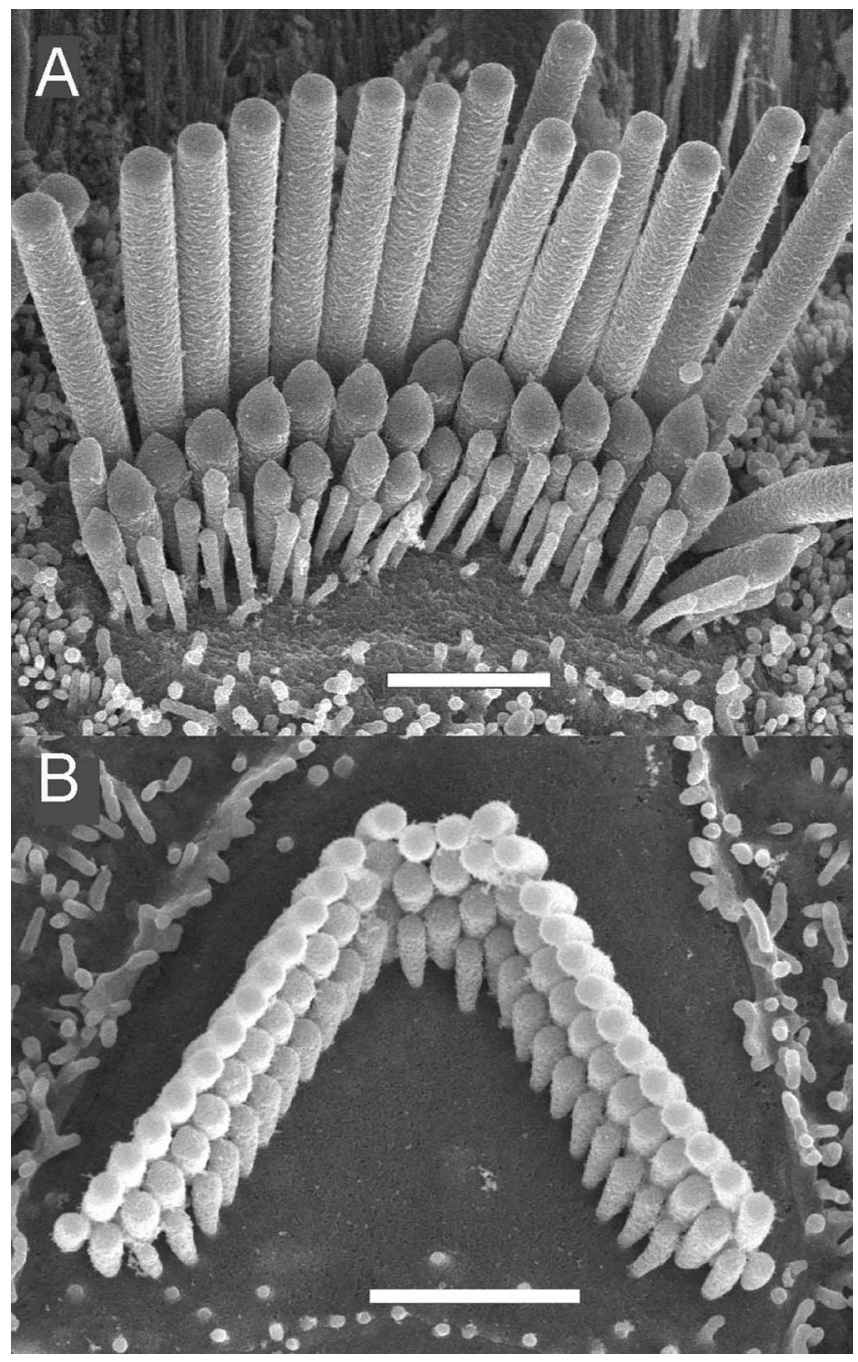

Figure 6. Scanning electron micrographs of hair bundles in the apical turn. $\boldsymbol{A}$, Inner hair cell. $\boldsymbol{B}$, First-row outer hair cell. Scale bars, $2.0 \mu \mathrm{m}$. These are representative examples of hair bundles from a P15 rat used for stereociliary and tip link counts.

from the amount of current carried by calcium. This was determined by replacing all monovalent ions in the normal artificial perilymph with an impermeant ion. When NMG was used as the impermeant ion (data not shown), the fraction of current carried by calcium, $I_{\mathrm{Ca}} / I_{\text {Total }}$, when its extracellular concentration was 1.5 mM was $0.15 \pm 0.02(n=5)$ in IHCs and $0.12 \pm 0.02(n=6)$ in $\mathrm{OHCs}$. These values are slightly lower than values measured previously in turtle auditory hair cells (Ricci and Fettiplace, 1998) and differ significantly from each other. To verify that NMG is effectively impermeant, reversal potentials for the MT current were measured in the NMG/1.5 $\mathrm{Ca}^{2+}$ solution. These were $-28.2 \pm 3.0(n=5)$ in IHCs and $-27.8 \pm 5.1(n=6)$ in OHCs. The reversal potentials were analyzed in terms of the GHK equation, inserting the appropriate values of $P_{\mathrm{Ca}} / P_{\mathrm{Cs}}$ determined above. This gave an average permeability of NMG relative to Cs of 0.1 , making NMG at least 50 times less permeable than $\mathrm{Ca}^{2+}$.

Both measurements of reversal potential and fraction of current carried by calcium suggest a slightly higher calcium permeability for the IHC channels, which have larger unitary conductance compared with $\mathrm{OHC}$ channels. To explore other differences in the MT channel permeability properties that might be linked to the differences in unitary conductance, we hypothe- size that the channel or its local membrane environment contains negative charges that play a role in controlling the conductance (Fig. 9A). Differences in these charges might influence the conductance by electrostatic mechanisms, as has been shown for the $\mathrm{BK} \mathrm{Ca}^{2+}$-activated $\mathrm{K}^{+}$channel (Brelidze et al., 2003) as well as affecting the calcium permeability. The BK channel contains a vestibule on its intracellular face, and replacement of negatively charged residues in the vestibule by noncharged ones halves the conductance (Brelidze et al., 2003). If similar charges on or around the MT channel act to concentrate the ions and there are differences in the charge distribution between IHCs and OHCs, then the effects of lowering the concentration of permeant ions in the extracellular solution should differentially affect the MT current. To test for this possibility, we lowered the sodium concentration to one-third by substitution with sucrose. The reduced ionic strength should augment the effects of the local charges by increasing the surface potential according to Gouy-Chapman theory (Jackson, 2006). On substitution of the low ionic strength medium, the MT current was reduced to $0.33 \pm 0.05(n=5)$ in $\mathrm{OHCs}$, a drop comparable with the dilution of the concentration in extracellular permeant ions. In contrast, the MT current in IHCs was reduced to $0.43 \pm 0.05(n=7)$, a significantly smaller decrease than for the OHCs (Fig. 9B). This result points to a difference in the MT channels of IHCs and OHCs and would be consistent with the existence of charges around the channel influencing ion permeation, which would augment the conductance by concentrating ions in the vestibule, increasing their availability to carry inward current.

\section{Discussion}

\section{MT channel conductance and permeability}

The mechanotransducer channel in mammalian auditory hair cells is characterized by a high selectivity for calcium, an inwardly rectifying current-voltage relationship, and an unusually large single-channel conductance. After allowing for an $\mathrm{Na}$ /Cs permeability ratio of 1.25 (Ohmori, 1985; Crawford et al., 1991), the $P_{\mathrm{Ca}} / P_{\mathrm{Na}}$ for the channel is $\sim 5: 1$. Inserting this permeability ratio into the GHK equation, the fraction of current carried by $1.5 \mathrm{~mm}$ calcium in normal Na-perilymph is calculated as 0.145 , not very different from that measured here by removing permeant monovalent ions (0.12-0.15). The agreement suggests that, to a first approximation, ion fluxes through the MT channel obey the constant field equation. Because the MT channel also exhibits calcium-dependent block, the conductance determined in 1.5 $\mathrm{mm}$ calcium solution needs correcting for this block. With a scaling factor of 1.52 (the increase in macroscopic current when the calcium is lowered to $0.02 \mathrm{~mm}$ ) (Fig. 7), single-channel cord conductance values $(-84 \mathrm{mV})$ for the unblocked channel are $262 \mathrm{pS}$ in IHCs and 145-210 pS in OHCs depending on cochlear location. If the trend in MT channel conductance in OHCs is extrapolated to the most basal high-frequency location [assuming a linear increase with distance from the apex as in the turtle (Ricci et al., 2003)], an upper limit of $\sim 320$ pS is expected. These unitary conductance values fall within the range reported previously for turtle auditory hair cells (Ricci et al., 2003), which also show tonotopic variation in MT channel amplitude.

\section{Channels per tip link}

We used estimates of the number of tip links, obtained indirectly from stereociliary counts excluding the tallest row, to relate the single-channel and macroscopic currents, thereby allowing a determination of the number of channels per tip link. Our analysis assumes that a single tip link emanates from the tip of each of the 
shorter stereocilia and that all stereocilia contain intact tip links. Nevertheless, the deduced values of between 1 and 2 are similar to other assessments in nonmammalian hair cells (Howard and Hudspeth, 1988; Denk et al., 1995; Ricci et al., 2003). Our experiments say nothing about the location of the channels with respect to the tip link. Denk et al. (1995) concluded that the channels were situated at both ends of the link, which implies that tip link destruction as a means of isolating channels would leave at least one link and therefore two channels. An alternative explanation arises from the apparent forking of the link at its upper or lower end seen in highresolution freeze-etched preparation (Kachar et al., 2000), which could permit each fork to connect to an individual channel, both channels being at one end of the link. However, in the present experiments, similar to those in turtle (Ricci et al., 2003), there were examples in which only a single channel remained after tip link destruction (Fig. 4). It is conceivable that, in these cases, the other channel of the pair was inactivated by a mechanism that did not affect the integrity of stimulus delivery to the residual channel. It might be argued that, if two channels were connected to a tip link, the opening to an identical mechanical stimulus would be to a two-channel level, implying that the single-channel amplitudes are overestimated. However, because of the stochastic nature of channel opening, it seems unlikely that both channels, whether at one or both ends of the tip link, would open simultaneously and have identical duration. The simplest conclusion is that the events such as those in Figure 4 represent single channels rather than doubles.

\section{Comparison with TRP channel properties}

Although the MT channel may belong to an as yet unknown class of ion channels, there is strong evidence that TRP channels behave as mechanoreceptors in a wide variety of organisms (Sukharev and Corey, 2004). However, few known TRP channel types satisfy the properties described here for the mammalian hair cell MT channel, and, even among the TRP channels, of those characterized, only the TRP polycystin (TRPP) subfamily has comparable properties (Owsianik et al., 2006). TRPP channels, mechanoreceptors that detect ciliary motion in renal epithelial cells and in the heart have $P_{\mathrm{Ca}} / P_{\mathrm{Na}}$ of up to 5 and unitary conductance up to $300 \mathrm{pS}$. Although there is no evidence as yet for the existence of TRPP channels in hair cells, other TRP channels have been found there, including TRP vanilloid receptor 4 (TRPV4) (Liedtke et al., 2000), TRP muclopins 3 (TRPML3) (Di Palma et al., 2002), and TRPA1 (Corey et al., 2004). TRPV4 has a unitary conductance of $\sim 90 \mathrm{pS}$ and a $P_{\mathrm{Ca}} / P_{\mathrm{Na}}$ of 6 (Strotmann et al., 2000), although a conductance of $300 \mathrm{pS}$ has also been reported (Liedtke et al., 2000). Its properties are not therefore too different from the MT channel, but TRPV4 knock-outs show no auditory defect (Liedtke and Friedman, 2003). TRPA1 has a unitary conductance of $<100 \mathrm{pS}$ in the absence of external calcium and a $P_{\mathrm{Ca}} / P_{\mathrm{Na}}$ of $\sim 1$ (Story et al., 2003; Nagata et al., 2005). No channel data are currently available for TRPML3, the mutation of which in the varitint-waddler mouse causes progressive hearing loss and hair cell degeneration (Di Palma et al., 2002). It is conceivable that the MT channel is a heteromer of subunits from two separate subfamilies: for example, TRPML and TRPP, which show substantial sequence similarity (Qian and Noben-Trauth, 2005). The existence of heteromeric channels might also provide a mechanism for variation in the unitary conductance. For example, if the MT channel were constructed from subunit A of low conductance and subunit $\mathrm{B}$ of high conductance, then five species of tetrameric channels would be possible: $A_{4}, A_{3} B, A_{2} B_{2}, A B_{3}$, and $B_{4}$.

It is possible that the high conductance channel $(B)$ is the one expressed in IHCs and the low conductance channel (A) the one in apical OHCs (Fig. 9). In pursuing this hypothesis, it would be desirable in the long term to show that MT channels of basal OHCs are similar to those of IHCs in terms of their conductance, calcium permeability, and response to lowered ionic strength. However, the difficulties of maintaining healthy hair cells in isolated basal coils have so far precluded our examining this question. MT channels in apical IHCs and OHCs, apart from their twofold difference in unitary conductance, are distinguishable in terms of the fraction of current carried by calcium and by the reduction in current on lowering the total concentration of permeant ions. One explanation is that IHC channels contain more negatively charged residues near the pore that concentrate ions 


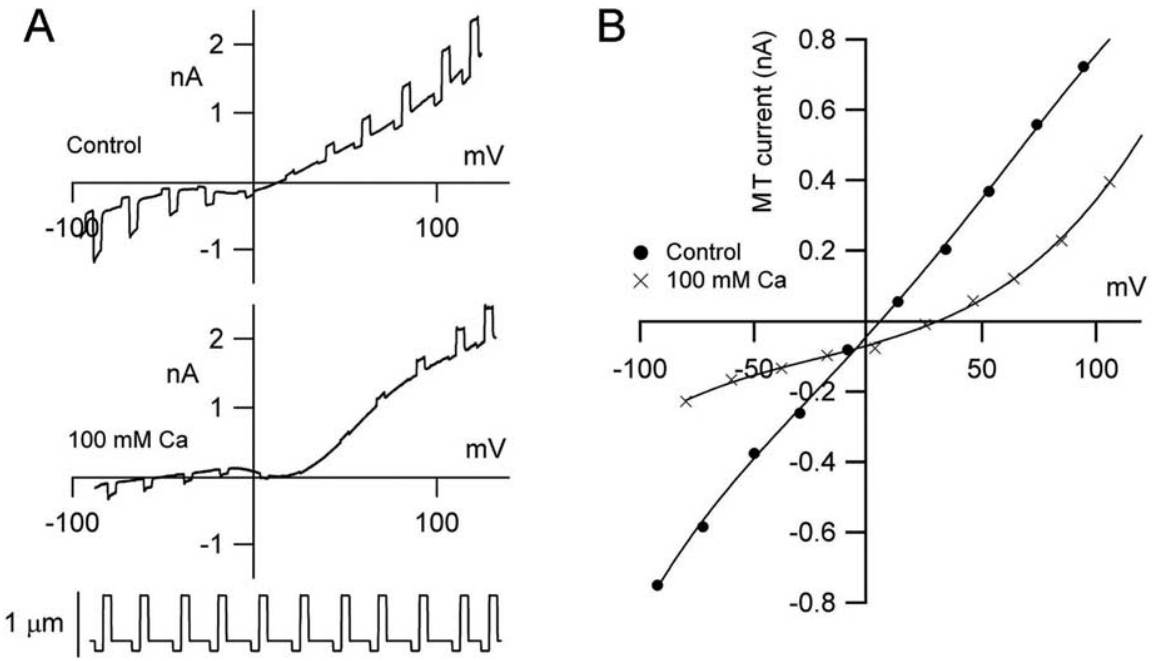

Figure 8. Reversal potential of inner hair cell MT current in normal and high calcium. $\boldsymbol{A}, \mathrm{MT}$ currents for saturating hair bundle deflections occurring during a voltage ramp: normal (1.5 mm) calcium saline (top), high (100 mm) calcium with no other permeant ion (middle), and bundle stimuli (bottom). $\boldsymbol{B}$, Current-voltage relationships for the MT channel in normal calcium (filled circles) and high calcium (crosses). The reversal potential was $+5 \mathrm{mV}$ in normal saline and $+31 \mathrm{mV}$ in $100 \mathrm{~mm}$ calcium. The postnatal age of the rat was P11.
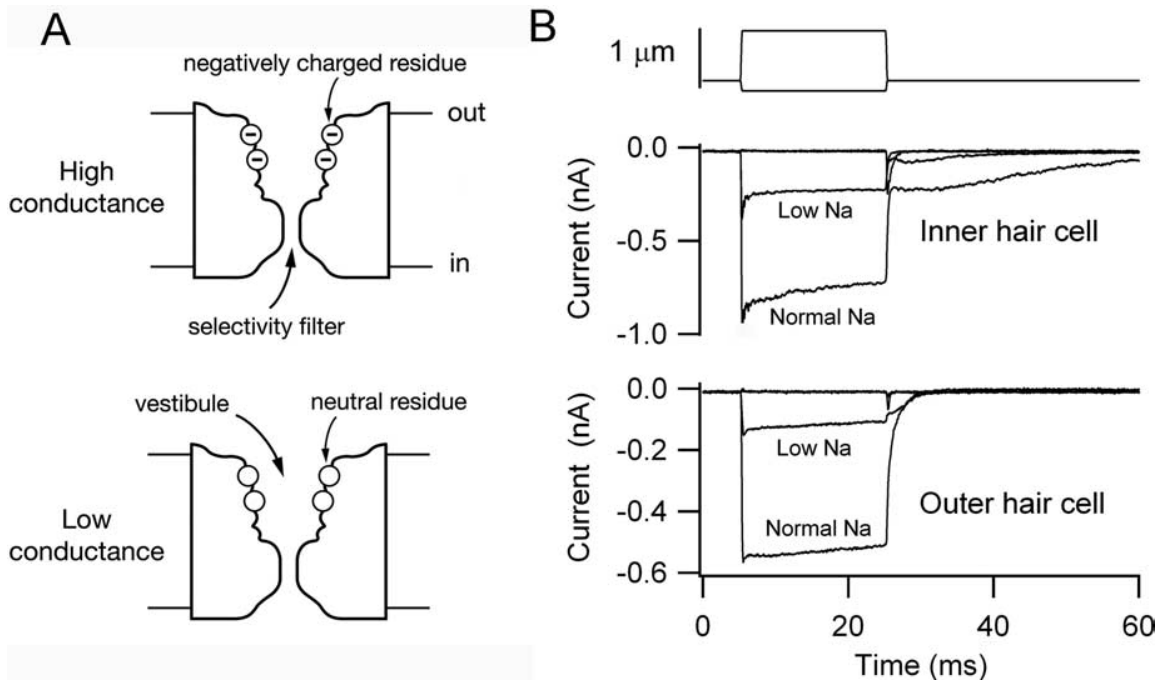

Figure 9. A model for differences in MT channel structure to account for variation in conductance and calcium permeability. $\boldsymbol{A}$, Hypothetical structure of the MT channel protein in a low conductance and high conductance channel. Negatively charged residues in a putative outer vestibule would locally concentrate the ions and increase channel conductance as found in BK channels (Brelidze et al., 2003). These residues may be absent on the low conductance version. The existence of a wide outer vestibule in the MT channel was suggested (Farris et al., 2004) on the basis of open channel block at the external surface by large molecules such as curare. $\boldsymbol{B}$, Effects of reducing the external sodium concentration and ionicstrength on MT currents in an apical IHC (top) and an apical OHC (bottom) that should differ twofold in their channel conductance. The fractional reduction in maximum current is larger in the $\mathrm{OHC}$. and in the geometry of the organ of Corti that increase the mechanical advantage between basilar membrane displacement and hair bundle rotation with CF (Dallos, 2003; He et al., 2004). However, MT channel conductance also influences the speed of fast adaptation, which is proportional to the calcium influx in individual stereocilia (Ricci et al., 2003): more calcium entering will produce a faster rate of adaptation in high-frequency OHCs. Fast adaptation is able to reset the operating range of MT channels, shifting the current-displacement relationship to optimize sensitivity. If fast adaptation is to filter out fluctuations at frequencies lower than the $\mathrm{CF}$, its time constant should vary inversely with the CF of the hair cell (Ricci et al., 2005). The tonotopic difference in adaptation time constants may also be important in adjusting the speed of force production by the $\mathrm{OHC}$ hair bundles in their contribution to cochlear amplification (Kennedy et al., 2005). This role may be unique to the OHCs because IHCs show no such tonotopic variation and their size or adaptation time constant. In vivo, the hair bundles of IHCs, unlike those of OHCs, are not directly attached to the tectorial membrane (Lim, 1980), and their motion is driven at least partly by the velocity of the surrounding fluid (Fridberger et al., 2006). Such coupling will mean that the stimulus is already highpass filtered, although this filtering will be sharpened by any adaptation in the transduction mechanism. However, the time constant of fast adaptation in IHCs is slower than in apical OHCs, although the MT channels have a larger unitary conductance. The speed of adaptation in IHCs might have been underestimated if the bundles were stimulated less efficiently; alternatively, there may be a difference in the adaptation process between the two types of hair cell. Understanding the source of the diversity is likely to require a definitive identification of the MT channel protein.

\section{References}

and increase unitary conductance. This is analogous to the BK channel in which negative charges in a vestibule near the pore also increase conductance (Brelidze et al., 2003). As with the BK channel, there was no difference in reversal potential between low and high conductance MT channels.

\section{Significance of differences in channel size}

What might be the functional significance of the differences in MT channel conductance? For the OHCs, it will generate larger macroscopic currents and hence greater sensitivity with an increase in CF. This effect will combine with the change in hair bundle size that halves from $\sim 5 \mu \mathrm{m}$ at the apical region recorded from to $\sim 2.5 \mu \mathrm{m}$ in the middle region (Roth and Bruns, 1992)
Assad JA, Shepherd GM, Corey DP (1991) Tip-link integrity and mechanical transduction in vertebrate hair cells. Neuron 7:985-994.

Bautista DM, Jordt SE, Nikai T, Tsuruda PR, Read AJ, Poblete J, Yamoah EN, Basbaum AI, Julius D (2006) TRPA1 mediates the inflammatory actions of environmental irritants and proalgesic agents. Cell 124:1269-1282.

Brelidze TI, Niu X, Magleby KL (2003) A ring of eight conserved negatively charged amino acids doubles the conductance of BK channels and prevents inward rectification. Proc Natl Acad Sci USA 100:9017-9022.

Bosher SK, Warren RL (1978) Very low calcium content of cochlear endolymph, an extracellular fluid. Nature 273:377-378.

Clapham DE, Julius D, Montell C, Schultz G (2005) International Union of Pharmacology. XLIX. Nomenclature and structure-function relationships of transient receptor potential channels. Pharmacol Rev 57:427-450. 
Corey DP, Hudspeth AJ (1979) Ionic basis of the receptor potential in a vertebrate hair cell. Nature 281:675-677.

Corey DP, Garcia-Añoveros J, Holt JR, Kwan KY, Lin SY, Vollrath MA, Amalfitano A, Cheung EL, Derfler BH, Duggan A, Geleoc GS, Gray PA, Hoffman MP, Rehm HL, Tamasauskas D, Zhang DS (2004) TRPA1 is a candidate for the mechanosensitive transduction channel of vertebrate hair cells. Nature 432:723-730.

Crawford AC, Fettiplace R (1985) The mechanical properties of ciliary bundles of turtle cochlear hair cells. J Physiol (Lond) 364:359-379.

Crawford AC, Evans MG, Fettiplace R (1989) Activation and adaptation of transducer currents in turtle hair cells. J Physiol (Lond) 419:405-434.

Crawford AC, Evans MG, Fettiplace R (1991) The actions of calcium on the mechano-electrical transducer current of turtle hair cells. J Physiol (Lond) 434:369-398.

Dallos P (1986) Neurobiology of cochlear inner and outer hair cells: intracellular recordings. Hear Res 22:185-198.

Dallos P (1992) The active cochlea. J Neurosci 12:4575-4585.

Dallos P (2003) Organ of Corti kinematics. J Assoc Res Otolaryngol $4: 416-421$.

Denk W, Holt JR, Shepherd GM, Corey DP (1995) Calcium imaging of single stereocilia in hair cells: localization of transduction channels at both ends of tip links. Neuron 15:1311-1321.

Di Palma F, Belyantseva IA, Kim HJ, Vogt TF, Kachar B, Noben-Trauth K (2002) Mutations in Mcoln3 associated with deafness and pigmentation defects in varitint-waddler (Va) mice. Proc Natl Acad Sci USA 99:14994-14999.

Eatock RA, Corey DP, Hudspeth AJ (1987) Adaptation of mechanoelectrical transduction in hair cells of the bullfrog's sacculus. J Neurosci 7:2821-2836

Farris HE, LeBlanc CL, Goswami J, Ricci AJ (2004) Probing the pore of the auditory hair cell mechanotransducer channel in turtle. J Physiol (Lond) 558:769-792.

Fettiplace R, Hackney CM (2006) The sensory and motor roles of auditory hair cells. Nat Rev Neurosci 7:19-29.

Fettiplace R, Ricci AJ (2003) Adaptation in auditory hair cells. Curr Opin Neurobiol 13:446-451.

Fettiplace R, Ricci AJ (2006) Mechanoelectrical transduction in auditory hair cells. Springer handbook of auditory research: vertebrate hair cells (Eatock RA, Fay RR, Popper AN, eds), pp 154-203. New York: Springer.

Fridberger A, Tomo I, Ulfendahl M, Boutet de Monvel J (2006) Imaging hair cell transduction at the speed of sound: dynamic behavior of mammalian stereocilia. Proc Natl Acad Sci USA 103:1918-1923.

Furness DN, Hackney CM (1985) Cross-links between stereocilia in the guinea pig cochlea. Hear Res 18:177-188.

Furness DN, Hackney CM (1986) High-resolution scanning-electron microscopy of stereocilia using the osmium-thiocarbohydrazide coating technique. Hear Res 21:243-249.

Géléoc GS, Lennan GW, Richardson GP, Kros CJ (1997) A quantitative comparison of mechanoelectrical transduction in vestibular and auditory hair cells of neonatal mice. Proc R Soc Lond B Biol Sci 264:611-621.

He DZZ, Jia S, Dallos P (2004) Mechanoelectrical transduction of adult outer hair cells studied in a gerbil cochlea. Nature 429:766-770.

Howard J, Hudspeth AJ (1988) Compliance of the hair bundle associated with gating of mechanoelectrical transduction channels in the bullfrog's saccular hair cell. Neuron 1:189-199.

Hudspeth AJ (1989) How the ear's works work. Nature 341:397-404.

Jackson MB (2006) Molecular and cellular biophysics. Cambridge, UK: Cambridge UP.

Kachar B, Parakkal M, Kurc M, Zhao Y, Gillespie PG (2000) Highresolution structure of hair-cell tip links. Proc Natl Acad Sci USA 97:13336-13341.

Kennedy HJ, Evans MG, Crawford AC, Fettiplace R (2003) Fast adaptation of mechanoelectrical transducer channels in mammalian cochlear hair cells. Nat Neurosci 6:832-836.

Kennedy HJ, Crawford AC, Fettiplace R (2005) Force generation by mammalian hair bundles supports a role in cochlear amplification. Nature 433:880-883.

Kros CJ, Rüsch A, Richardson GP (1992) Mechano-electrical transducer currents in hair cells of the cultured neonatal mouse cochlea. Proc R Soc Lond B Biol Sci 249:185-193.
Kros CJ, Marcotti W, van Netten SM, Self TJ, Libby RT, Brown SD, Richardson GP, Steel KP (2002) Reduced climbing and increased slipping adaptation in cochlear hair cells of mice with Myo7a mutations. Nat Neurosci 5:41-47.

Kwan KY, Allchorne AJ, Vollrath MA, Christensen AP, Zhang DS, Woolf CJ, Corey DP (2006) TRPA1 contributes to cold, mechanical, and chemical nociception but is not essential for hair-cell transduction. Neuron 50:277-289.

Liedtke W, Friedman JM (2003) Abnormal osmotic regulation in trpv4-/mice. Proc Natl Acad Sci USA 100:13698-13703.

Liedtke W, Choe Y, Marti-Renom MA, Bell AM, Denis CS, Sali A, Hudspeth AJ, Friedma JM, Heller S (2000) Vanilloid receptor-related osmotically activated channel (VR-OAC), a candidate vertebrate osmoreceptor. Cell 103:525-535.

Lim DJ (1980) Cochlear anatomy related to cochlear micromechanics. A review. J Acoust Soc Am 67:1686-1695.

Marcotti W, Johnson SL, Kros CJ (2004) Effects of intracellular stores and extracellular $\mathrm{Ca}^{2+}$ on $\mathrm{Ca}^{2+}$-activated $\mathrm{K}^{+}$currents in mature mouse inner hair cells. J Physiol (Lond) 557:613-633.

Müller M (1991) Frequency representation in the rat cochlea. Hear Res $51: 247-254$.

Nagata K, Duggan A, Kumar G, Garcia-Añoveros J (2005) Nociceptor and hair cell transducer properties of TRPA1, a channel for pain and hearing. J Neurosci 25:4052-4061.

Ohmori H (1985) Mechano-electrical transduction currents in isolated vestibular hair cells of the chick. J Physiol (Lond) 359:189-217.

Owsianik G, Talavera K, Voets T, Nilius B (2006) Permeation and selectivity of trp channels. Annu Rev Physiol 68:685-717.

Pickles JO, Comis SD, Osborne MP (1984) Cross-links between stereocilia in the guinea pig organ of Corti, and their possible relation to sensory transduction. Hear Res 15:103-112.

Pyott SJ, Glowatzki E, Trimmer JS, Aldrich RW (2004) Extrasynaptic localization of inactivating calcium-activated potassium channels in mouse inner hair cells. J Neurosci 24:9469-9474.

Qian F, Noben-Trauth K (2005) Cellular and molecular function of mucolipins (TRPML) and polycystin 2 (TRPP2). Pflügers Arch 451:277-285.

Ricci AJ, Fettiplace R (1997) The effects of calcium buffering and cyclic AMP on mechano-electrical transduction in turtle auditory hair cells. J Physiol (Lond) 501:111-124.

Ricci AJ, Fettiplace R (1998) Calcium permeation of the turtle hair cell mechanotransducer channel and its relation to the composition of endolymph. J Physiol (Lond) 506:159-173.

Ricci AJ, Crawford AC, Fettiplace R (2002) Mechanisms of active hair bundle motion in auditory hair cells. J Neurosci 22:44-52.

Ricci AJ, Crawford AC, Fettiplace R (2003) Tonotopic variation in the conductance of the hair cell mechanotransducer channel. Neuron 40:983-990.

Ricci AJ, Kennedy HJ, Crawford AC, Fettiplace R (2005) The transduction channel filter in auditory hair cells. J Neurosci 25:7831-7839.

Robinson RA, Stokes RH (1965) Electrolyte solutions. London: Butterworth.

Roth B, Bruns V (1992) Postnatal development of the rat organ of Corti. II. Hair cell receptors and their supporting elements. Anat Embryol 185:571-581.

Russell IJ, Sellick PM (1978) Intracellular studies of hair cells in the mammalian cochlea. J Physiol (Lond) 284:261-290.

Russell IJ, Cody AR, Richardson GP (1986) The responses of inner and outer hair cells in the basal turn of the guinea-pig cochlea and in the mouse cochlea grown in vitro. Hear Res 22:199-216.

Russell IJ, Kössl M, Richardson GP (1992) Nonlinear mechanical responses of mouse cochlear hair bundles. Proc R Soc Lond B Biol Sci 250:217-227.

Skinner LJ, Enee V, Beurg M, Jung HH, Ryan AF, Hafidi A, Aran JM, Dulon D (2003) Contribution of $\mathrm{BK} \mathrm{Ca}^{2+}$-activated $\mathrm{K}^{+}$channels to auditory neurotransmission in the guinea pig cochlea. J Neurophysiol 90:320-332.

Story GM, Peier AM, Reeve AJ, Eid SR, Mosbacher J, Hricik TR, Earley TJ, Hergaden AC, Andersson DA, Hwang SW, McIntyre P, Jegla T, Bevan S, Patapoutian A (2003) ANKTM1, a TRP-like channel expressed in nociceptive neurons is activated at cold temperatures. Cell 112:819-829.

Strotmann R, Harteneck C, Nunnenmacher K, Schultz G, Plant TD (2000) OTRPC4, a nonselective cation channel that confers sensitivity to extracellular osmolarity. Nat Cell Biol 2:695-702.

Sukharev S, Corey DP (2004) Mechanosensitive channels: multiplicity of families and gating paradigms. Sci STKE 219:1-24. 